\title{
Understanding Gender Differences in Online Learning
}

\author{
Dr. Julie Little-Wiles, Dr. Eugenia Fernandez, and Prof. Patricia Fox \\ Indiana University-Purdue University (IUPUI) \\ Indianapolis, IN \\ jlwiles95@gmail.com,efernand@iupui.edu,psfox@iupui.edu
}

\begin{abstract}
As virtual learning has become increasingly more popular and even more common within both two and four-year institutions, the question of student engagement within these courses remains a critical factor for both administrators and faculty. Determining how students respond and participate in online courses has been studied to some degree, but what has not specifically been addressed is the factor of gender. So simply asked: Does gender play a significant role in how students engage with online courses? This question directed a two year study that sought to determine if gender does play a role in the engagement and student success in one online sophomore-level ethical decision-making course taught at the School of Engineering and Technology at Indiana University-Purdue University Indianapolis. This paper will outline the various phases of the project including initial set-up and planning, the pilot study, and then the full launch to all sections each semester. The data examined includes students' gender, total site activity and usage, total site visits, chat room activity, message activity, course letter grade, and course letter grade percentage earned. Basic demographics will be determined and statistical analysis will be performed at each stage of the study with a final conclusion drawn at the end of the two years. This two-year study is organized into four phases. Currently, phases one and two are complete with phase two, the pilot study, garnering some interesting results for the research team. Phase three, the full launch to all sections in two semesters, is now underway and the researchers hope the full launch will determine if the pilot results were correct or if a larger sample provides a clearer determination in regards to gender.
\end{abstract}

Keywords: Online Learning, Gender, Learning Management Systems

\section{INTRODUCTION}

As the popularity of both online courses and programs continues to strengthen, student engagement questions persist, especially in regard to the engagement comparable to those same courses that are taught face-to-face (F2F). As it has been determined that student engagement leads to "undergraduate academic achievement, student attrition, student retention, student motivation and institutional success" [1], it becomes a crucial element for all courses and programs to possess. Part of the issue concerning student engagement within online courses is the perceived inadequacies that online courses may have in a learning management system (LMS). Often, online courses are taught in an asynchronous environment only for the convenience of students due to both their work and family responsibilities, while still other courses or programs attempt to merge in elements of synchronous chats or discussions to facilitate some sort of interaction students' desire.

As those in higher education attempt to find the perfect balance within online courses and programs to engage their students in the same or comparable manner to their F2F counterparts, but the questions remains: are students responding differently in an online environment? While we understand a F2F classroom can be a richer learning environment, consequently as instructors we strive to duplicate those same learning processes for our online students providing that same rich experience. But are the environments the only difference for students? Are there possible learning differences online between our students we haven't considered? Are males and females possibly reacting in a different way to the material and methods presented?

These questions led researchers to explore this topic with the launch of a two year study at the School of Engineering and Technology at Indiana University-Purdue University Indianapolis that sought to determine if gender was a significant factor in student engagement in one online sophomore level, ethical decision-making course.

\section{FRAMEWORK}

Researchers focused on examining what studies had previously already defined in regards to gender differences online to provide a better understanding of the context the study encompassed.

Unfortunately, very little research presently exists in respect to gender engagement differences within online courses or programs so that researchers had a point of reference for their current study. Most studies were at least five to ten years old, obviously conducted at the peak of the launch of online learning and learning management systems, and a good deal of them concentrated on information technology courses $[1,2]$. There are some notable findings, however, as Beer, Clark and Jones determined in their work that learning environments did indeed influence engagement as well as gender [1]. As traditionally females represent a lower percentage in any engineering, technology or computer course, McSporran and Young found that females scored higher in both assessments (assignments and quizzes) and the final exam then males over a four semester study of one "Internet and Web Design first-year introductory course in the Bachelor of Computing Systems degree" at their particular

This is the author's manuscript of the article published in final edited form as:

Little-Wiles, J., Fernandez, E., \& Fox, P. (2014). Understanding gender differences in online learning. In 2014 IEEE Frontiers in Education Conference (FIE) (pp. 1-4). http://doi.org/10.1109/FIE.2014.7044069 
institution [2].

As we were previously educated that the Internet has provided each person a place to communicate in the same manner regardless of our gender [3, 4], Monteith counters this thought with her study determining that gender was "not masked in the text driven discussions on the Internet" and that "the virtual classroom is becoming a female domain" [5]. Goldberg also reveals that more females are seeking online courses to close the gender gap presented in F2F classrooms [6]. Another larger study from Garland and Martin compromising 168 students in seven upper-level undergraduate online courses produced significant results as the data revealed that not only "gender can be a factor in online learning" but also that it "supports the need for including gender equity in building and designing courses and programs" [7].

With this context in mind, we examine gender to determine if it does indeed impact student engagement within an online environment in our two-year study.

\section{The PRoJect}

Since the greater goals for this project are to better understand if gender plays a significant role student engagement within online courses within a learning management system, we must complete several stages in order to reach a final recommendation on elements crucial to the project goals.

Our project is divided into the following four stages:

- Stage One - The development of the study within the selected course, OLS26300 Ethical Decisions in Leadership. This includes the selection of data within the LMS for statistical analysis, and the creation of the student survey for additional assessment. Finally internal approval from the institutional review board at the university was sought and granted for the study.

- Stage Two - In order to test the study design, a pilot study was launched within two online sections of OLS26300 during fall 2012. The pilot included both the LMS statistics and student survey for both sections.

- Stage Three - The continued launch of the study each semester with all online sections of OLS26300 from spring 2013 until fall 2014, the conclusion of the two year study currently.

- Stage Four - The final comparison of survey results and student remarks with final recommendations and a determination if the study should be extended.

Stage One was completed in the summer 2012 as the researchers at the School of Engineering and Technology at Indiana University-Purdue University Indianapolis prepared the study, and the project subsequently was planned. In order to determine if gender plays a significant role within student engagement two methods of data collection were established. First, data within the Learning Management System (LMS) was selected for statistical analysis including: students' gender, total site activity and usage, total site visits, chat room activity, message activity, course letter grade, and course letter grade percentage earned. Second, both a student and faculty survey was developed to determine student and faculty reaction to student engagement within the online course for each and every section each semester the course was to be offered.

Fall 2012 observed the completion of Stage Two, the pilot study, with the first initial two online sections launched testing the study design for the researchers. Overall results proved interesting, and will be discussed in Section IV, The Pilot Study.

Currently, Stage Three is ongoing and will continue through the end of fall 2014. This includes online sections that will be held during summer 2014.

A final comparison of all results and remarks will conclude during Stage Four during the spring of 2015, providing researchers with a small scale example of online student engagement and possible gender differences to reach a final recommendation.

\section{The PILOT StUdy}

For the pilot study data was collected on 49 students (12 females, 37 males) in two online sections of OLS 26300. Students' final grades were collected along with total site usage, total chat activity, total message activity, and total site visits within the LMS. Averages of these variables by gender appear in Table 1.

TABLE 1

MEAN OF STUDY VARIABLES BY GENDER

\begin{tabular}{|l|c|c|}
\hline Variable & Females & Males \\
\hline Mean Total Site Activity & 552.6 & 400.3 \\
\hline Mean Total Site Visits & 143.9 & 109.8 \\
\hline Mean Chat Activity & 134.3 & 133.3 \\
\hline Mean Message Activity & 64.8 & 55.6 \\
\hline Mean Course Grade \% & $86.3 \%$ & $89.4 \%$ \\
\hline Corresponding Letter Grade & B & B+ \\
\hline
\end{tabular}

The data was used to investigate the following four questions:

1. Is there a relationship between gender and the students' final course grade?

2. Is there a relationship between gender and total visits with the students' final course grades?

3. Is there a relationship between gender and LMS functions (total site visits, total site activity, chat activity, message activity)?

4. Is there a difference between the pattern of how each gender utilized the LMS functions?

\section{Gender and final course grades}

To investigate the effect of gender on final course grade an independent-samples $t$ test was calculated comparing the mean grade of male students to the mean grade of female 
students. No significant difference was found $(t(47)=.549$, $p>.05)$.

\section{Final course grades by gender and total site visits}

To determine if gender and total site visits impacted final course grade, a two factor ANOVA was conducted. To do so, total site visits were coded into four categories: High, Above Average, Below Average, and Low. The total site visit quartiles were used to place each student into one of these categories (see Table 2).

TABLE 2

TOTAL SITE VISITS AND MEAN GRADES BY QUARTILES
\begin{tabular}{|l|c|c|}
\hline $\begin{array}{c}\text { Total Site Visit } \\
\text { Category }\end{array}$ & Percent & $\begin{array}{c}\text { Mean } \\
\text { Grade }\end{array}$ \\
\hline Low & 26.5 & $75.1 \%$ \\
\hline Below Average & 26.5 & $91.3 \%$ \\
\hline Above Average & 22.4 & $95.6 \%$ \\
\hline High & 24.5 & $94.1 \%$ \\
\hline
\end{tabular}

A 2 (gender) $\times 4$ (total site visit category) betweensubjects factorial ANOVA was calculated comparing the final course grades for male and female students and the frequency of their visits to the LMS. The main effect for gender was significant $(F(1,41)=4.48, p<.05)$. The main effect for total site visits frequency was significant $(F(3,41)=14.291, p<$ $.001)$. Tukey's HSD post hoc tests were used to determine the nature of the differences. Students with low visit frequency had significantly lower grades than did those with below average, above average or high visit frequency. The interaction was significant $(F(3,41)=5.60, p<.05)$. As shown in Figure 1, female students with low visit frequency earned significantly lower grades $(\mathrm{m}=41.2$, $\mathrm{sd}=8.31)$ than male students with low visit frequency $(\mathrm{m}=81.3, \mathrm{sd}=3.55)$.

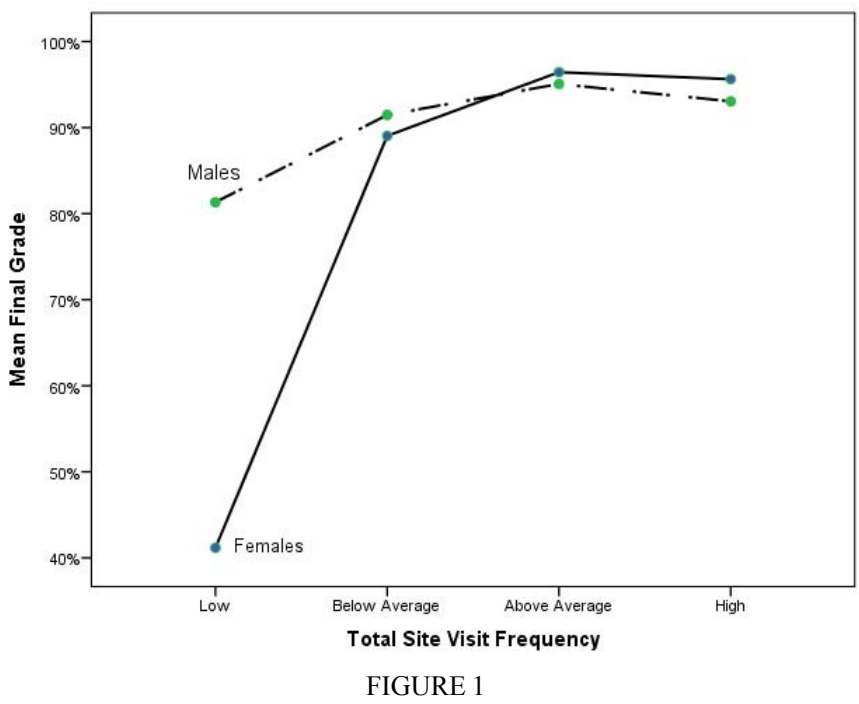

INTERACTION OF GENDER AND TOTAL Site Visit ON FinAL GRADES
As the main effect results for gender and final grade contradict the previous $t$ test results, a closer examination of the data revealed 3 clear outliers for final grade (see Figure 3 ). When these 3 students ( 2 females, 1 male) were removed from the factorial ANOVA analysis, no significant results were found. This indicates that the small female sample size does not provide enough data for a conclusion regarding significance of gender in this analysis.

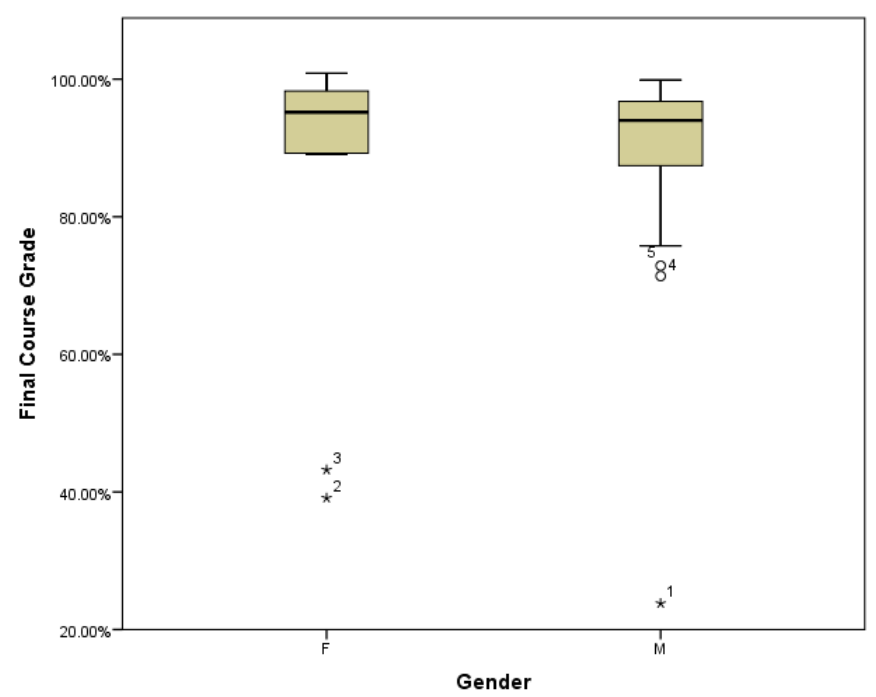

FIGURE 2

Final Course Grade Box Plot By Gender Shows 3 OutLIERS

\section{Gender and LMS functions}

Independent samples $t$ tests were calculated comparing the male and female means for each of the LMS functions: total site activity, total site visits, chat room activity, and message activity. No significant differences were found (see Table 3).

TABLE 3

INDEPENDENT T TEST RESULTS FOR LMS FUNCTION BY GENDER

\begin{tabular}{|c|c|c|c|c|c|c|}
\hline & Gender & Mean & $\begin{array}{l}\text { Std. } \\
\text { Dev. }\end{array}$ & $t$ & df & Sig. \\
\hline \multirow{2}{*}{$\begin{array}{l}\text { Total Site } \\
\text { Activity }\end{array}$} & M & 552.6 & 162.9 & \multirow[t]{2}{*}{1.240} & \multirow[t]{2}{*}{12.12} & \multirow[t]{2}{*}{.238} \\
\hline & $\mathrm{F}$ & 400.3 & 415.2 & & & \\
\hline \multirow{2}{*}{$\begin{array}{l}\text { Total Site } \\
\text { Visits }\end{array}$} & M & 109.8 & 55.09 & \multirow[t]{2}{*}{1.812} & \multirow[t]{2}{*}{47} & \multirow[t]{2}{*}{.076} \\
\hline & $\mathrm{F}$ & 143.9 & 61.64 & & & \\
\hline \multirow{2}{*}{$\begin{array}{l}\text { Chat Room } \\
\text { Activity }\end{array}$} & M & 133.3 & 78.30 & \multirow[t]{2}{*}{.040} & \multirow[t]{2}{*}{47} & \multirow[t]{2}{*}{.968} \\
\hline & $\mathrm{F}$ & 134.3 & 66.96 & & & \\
\hline \multirow{2}{*}{$\begin{array}{l}\text { Message } \\
\text { Activity }\end{array}$} & M & 55.65 & 31.49 & \multirow[t]{2}{*}{.941} & \multirow[t]{2}{*}{47} & \multirow[t]{2}{*}{.352} \\
\hline & $\mathrm{F}$ & 64.75 & 19.42 & & & \\
\hline
\end{tabular}

The high standard deviation in total site activity led to further analysis identifying 3 clear outliers ( 2 females and 1 male). Referring to the SPSS data analysis, it was noted that the $t$ test for total site activity did not meet the Levene's Test 
for Equality of Variances $(F(47)=8.130, p<.05)$ However, when these three outliers were removed, Levene's test was satisfied $(F(44)=.649, \mathrm{p}>.05)$. The outliers were removed and the independent $t$ test was re-calculated comparing male and female means for total site activity. No significant difference was found $(t(44)=-.003, p>.05)$. The mean total site activity of male students $(m=383.6, s d=128.9)$ was not significantly different from the mean total site activity of female students ( $m=383.4, s d=110.2)$. These three outliers were removed for any subsequent analysis involving total site activity.

\section{Gender and pattern of usage across all LMS functions}

A chi-square test of independence was calculated comparing gender to the pattern of mean usage totals across all LMS functions (as shown in Table 4). No significant relationship was found $\left(X^{2}(3)=3.91, p>.05\right)$. Gender and pattern of usage of LMS functions appear to be independent.

TABLE 4

\begin{tabular}{|c|c|c|c|c|}
\multicolumn{1}{c|}{ MEAN ACTIVITY TOTALS BY GENDER } \\
\hline Gender & $\begin{array}{c}\text { Total Site } \\
\text { Activity }\end{array}$ & $\begin{array}{c}\text { Total Site } \\
\text { Visits }\end{array}$ & $\begin{array}{c}\text { Chat } \\
\text { Room } \\
\text { Activity }\end{array}$ & $\begin{array}{c}\text { Message } \\
\text { Activity }\end{array}$ \\
\hline F & 383.40 & 143.92 & 134.33 & 64.75 \\
\hline M & 383.60 & 109.78 & 133.32 & 55.65 \\
\hline
\end{tabular}

\section{Conclusion of pilot study}

Analysis was conducted to determine if there was a relationship between gender and the students' final grade (independent samples $t$ test), if there was any relationship between gender and total visits with the students' final grade (factorial ANOVA), if there was a dependence between gender and LMS functions (independent samples $t$ test), and if there was a difference between how each gender utilized the LMS functions (chi-square test of independence). The only significant credible result was related to total site visit frequency and course grade. Not surprisingly, students who visited the LMS site less frequently earned lower grades than other students.

The lack of gender differences in course grades and LMS usage is consistent with Beer, Clark and Jones' [1] work, but contradicts McSporran and Young's results which showed women earning higher grades in an online course [2]. Based on our conflicting results, and our small female sample size $(n=12)$, we conclude not enough data has been collected to appropriately draw meaningful conclusions. Collecting larger samples may provide different results than the analysis of this study found. A complete description of our pilot study can be found in [8].

\section{FINAL REMARKS}

As both Stages One and Two are now complete, researchers are eager to continue with the study through the final stages to determine if the early results from the pilot study are consistent throughout the project or newer findings will emerge with the launch of all online sections in the final semesters. Researchers are also hopeful that the additional sets of results will continue to reveal details to assist them in answering the research question posed by the study.

\section{REFERENCES}

[1] Beer, C., \& Clark, K., \& Jones, D. (2010). Indicators of engagement. In C.H. Stee, M.J. Keppell, P. Geric \& Housego (Eds.), Curriculum, technology \& transformation for an unknown future. Proceedings ascilite Sydney 2010, 75-86. Retrieved from http://www.ascilite.org.au/conferences/sydney10/procs/Beer-full.pdf

[2] McSporran, M., \& Young, S. (2001). Does gender matter in online learning? Research in Learning Technology, 9(2), 3-15. doi: $10.1080 / 0968776010090202$

[3] Finke, L. (2001). Women: Lost in Cyberspace? Retrieved from: http://www.enhanced-learning.org/prox/paper5.htm

[4] King, L.J. (2000). Gender issues in online communities. Computer Professionals for Social Responsibility, 18(1) Retrieved from: http://www.cpsr.org/publications/newsletters/issues/2000/Winter2000/ki ng.html

[5] Monteith, K. (2002). Gendered learning and learning about gender online: A content analysis of online discussion. An ODELUCE, University of Stirling Report. Retrieved from http://www.odeluce.stir.ac.uk/docs/ Gendered\%20Learning.pdf

[6] Goldberg, R. (2012, November 28). Women now outnumber men in college: How online education might help the gender gap. Retrieved from http://www.policymic.com/articles/19734/women-now-outnumbermen-in-college-how-online-education-might-help-the-gender-gap

[7] Garland, D. \& Martin, B. (2005). Do gender and learning style play a role in how online courses should be designed? Journal of Interactive Online Learning, 4(2), 67-81. Retrieved from http://www.ncolr.org/ jiol/issues/pdf/4.2.1.pdf

[8] Hutson-Stone, A.D., Little-Wiles, J.M., Fernandez, E., \& Fox, P. (2014). Student engagement online - does gender make a difference? A pilot study in one engineering and technology course. Proceedings of the 2014 ASEE Annual Conference, June15-18, Indianapolis, IN. 